\title{
Numerical Investigations of Film Cooling Effect on Sub-Scale Rocket Engine Performance*
}

\author{
By Takashi ITO, Nobuyuki TsuboI ${ }^{\dagger}$ and Hiroshi MiYaJIMA \\ Japan Aerospace Exploration Agency, Sagamihara, Japan
}

(Received June 13th, 2009)

\begin{abstract}
$\mathrm{LOX} / \mathrm{LH}_{2}$ subscale rocket nozzle flow fields are simulated computationally using the 3D compressible NavierStokes equations. The area ratio of the nozzle is 140 and the film coolant hydrogen gases are injected from 30 film cooling holes distributed circumferentially at an area ratio of 13 . The experimental nozzle throat Reynolds number indicates that the boundary layer of the nozzle is in its transition region as the size of the nozzle is small. A clear difference in effective specific impulses of the secondary flow between the laminar and turbulent conditions is also shown. The nozzle wall temperature also influences the nozzle performance and the experimental performances were in better agreement with the laminar computations when the wall temperature is set to $300 \mathrm{~K}$, which is closer to the experimental conditions. Both turbulent and laminar computations are carried out to investigate the effect of the boundary layer conditions on the nozzle performance. The computed results show that the structure of the separated flow downstream of the film cooling injection significantly changes between the turbulent and laminar conditions.
\end{abstract}

Key Words: Propulsion, Rocket Nozzle, Computational Fluid Dynamics, Specific Impulse, Film Cooling

\section{Introduction}

Rocket engines that use a gas generator to generate turbine exhaust gas usually dump the gas around the nozzle with a separate duct from the main flow. The turbine exhaust gas is typically discharged overboard through one or two separate small low-area ratio nozzles. Alternatively, this turbine exhaust can be injected into the main flow through openings in the diverging nozzle section. By selecting this configuration, a compact and lightweight engine packaging becomes possible. If the engine is to be used for an upper stage of a launch vehicle, that configuration conveniently solves the separate localized secondary flow diffuser design problem for altitude firing test facility. The LE-5B engine, which powers the second stage of the H-IIA launch vehicle, injects the turbine exhaust gas into the main flow as film coolant and the gas then protects the outermost nozzle extension wall from high temperatures.

Studies on the effect of rocket engine film cooling on engine performance in Japan were carried out by Miyajima et al. at Kakuda Space Center's high altitude test stand in 1984. ${ }^{1)} \mathrm{LH}_{2}$ and LOX were used as propellants and both the specific impulse and the heat flux characteristics were investigated. However, there were no detailed discussions on the flow field producing the specific impulse and heat flux characteristics. Recent studies on the film cooling effect using the CFD method have discussed the validity of the turbulence model by comparing the nozzle performance using different turbulence models. ${ }^{2)}$ However, there are still few

(C) 2010 The Japan Society for Aeronautical and Space Sciences

*Translated from Journal of the Japan Society for Aeronautical and Space Sciences, Vol. 56, No. 659, 2008, pp. 551-557

Currently Kyushu Institute of Technology, Kitakyushu, Japan detailed discussions on the effect of the nozzle flow field on the nozzle performance. The main aim of film cooling is to lower the heat load on the nozzle and discussion tends to focus on structure and heat problem when dealing with these problems. Therefore, there are few studies on the flow field itself.

In this study, computation was performed to investigate the effects of turbine exhaust (film coolant) injected into the rocket nozzle on the nozzle performance. The CFD computation was validated by comparing the CFD result and experiments. The high-temperature nozzle wall effect is discussed by considering application to the full-scale nozzle. The detailed flow field inside the nozzle is discussed to investigate the flow mechanism producing the thrust performance.

\section{Test Hardware and Procedure}

\subsection{Test hardware}

Figure 1 shows the schematic of the thrust chamber assembly used for the turbine exhaust (film cooling) injection simulation test. ${ }^{1)}$ It uses a water-cooled oxygen/hydrogen thrust chamber with a nominal thrust of $3950 \mathrm{~N}$ at a chamber pressure of 3.4 MPa. The detailed configuration is described elsewhere. ${ }^{1)}$ The mixture ratio (oxidizer mass flow/fuel mass flow) of the primary flow is set to 5.5. The overall primary nozzle area ratio is $140: 1$. The film coolant which is gaseous hydrogen at normal temperature, is injected through 30 discrete holes at a primary area ratio of $13: 1$, as shown in Fig. 1. The nozzle extension consists of three segments with a total of 12 circumferential coolant passages to facilitate measurement of semi-local heat fluxes and are flangeconnected to the first segment at an area ratio of 8 . 


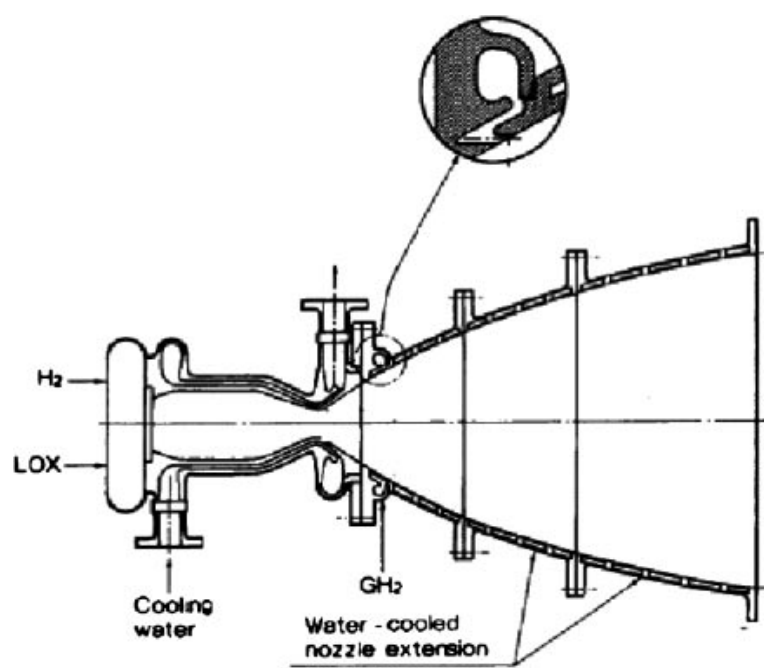

Fig. 1. Thrust chamber assembly.

Tests were conducted to simulate the effects of turbine exhaust on engine specific impulse of the LE-5 engine at approximately $1 / 5$ scale. However, due to incorporation of hardware from previous programs and the difficulty of fabricating injection slits, the turbine exhaust region did not represent an exact $1 / 5$ scale model of the LE-5. In the full-scale engine, there are 50 discrete slits on the base of a back step at a primary nozzle area ratio of $8.5: 1$; the geometry of the injection step is formed by cutting a step off the otherwise smooth optimum thrust contour. ${ }^{3)}$ Despite these geometrical differences, we believed meaningful data could be obtained by hot-firing tests because discussions focuses on the effect of the film cooling injection (secondary flow) on the nozzle performance.

\subsection{Required precision and test procedure}

The engine specific impulse $\left(I_{\mathrm{E}}\right)$ and effective specific impulse of the secondary flow $\left(I_{\mathrm{S}}\right)$ are related as follows:

$$
I_{\mathrm{E}}=\left(I_{\mathrm{p}} \dot{m}_{\mathrm{p}}+I_{\mathrm{s}} \dot{m}_{\mathrm{s}}\right) /\left(\dot{m}_{\mathrm{p}}+\dot{m}_{\mathrm{s}}\right)
$$

or

$$
I_{\mathrm{s}}=I_{\mathrm{E}}-\left(\dot{m}_{\mathrm{p}} / \dot{m}_{\mathrm{s}}\right)\left(I_{\mathrm{p}}-I_{\mathrm{E}}\right)
$$

where, $I_{\mathrm{p}}$ represents the main flow specific impulse, $\dot{m}$ represents the mass flow rate and the subscripts $\mathrm{p}$ and $\mathrm{s}$ represent the main and secondary flow, respectively.

The variances of the measured value $x, y, z, \cdots$ are $\sigma_{x}, \sigma_{y}$, $\sigma_{z}, \cdots$ If $x, y, z, \cdots$ are independent variables, the propagation of $f(x, y, z, \cdots)$ to the variance $\sigma_{f}$ can be expressed ${ }^{4,5)}$ as

$$
\sigma_{f}^{2}=\left(\frac{\partial f}{\partial x}\right)^{2} \sigma_{x}^{2}+\left(\frac{\partial f}{\partial y}\right)^{2} \sigma_{y}^{2}+\left(\frac{\partial f}{\partial z}\right)^{2} \sigma_{z}^{2}+\cdots
$$

From Eq. (2), the effective specific impulse of the secondary flow is a function of engine specific impulse $\left(I_{\mathrm{E}}\right)$ and the main flow specific impulse, or the specific impulse without the secondary flow $\left(I_{\mathrm{p}}\right)$. The variation of $I_{\mathrm{E}}$ and $I_{\mathrm{p}}$ can be considered the same, so $\sigma_{I_{\mathrm{E}}}{ }^{2}$ is substituted for ${\sigma_{I_{\mathrm{p}}}}^{2}$.

Dividing variation by the mean value and defining the precision $P_{\mathrm{r}}$, the precision of $I_{\mathrm{S}}$ and $I_{\mathrm{E}}$ can be expressed as follows:

$$
P_{\mathrm{r}\left(I_{\mathrm{s}}\right)}=\frac{\sigma_{I_{\mathrm{s}}}}{I_{\mathrm{s}}} \quad P_{\mathrm{r}\left(I_{\mathrm{E}}\right)}=\frac{\sigma_{I_{\mathrm{E}}}}{I_{\mathrm{E}}}
$$

Equation (3) can now be written using Eq. (4) as

$$
P_{\mathrm{r}\left(I_{\mathrm{s}}\right)}=\sqrt{2}\left(\frac{\dot{m}_{\mathrm{p}}}{\dot{m}_{\mathrm{s}}}\right) P_{\mathrm{r}\left(I_{\mathrm{E}}\right)} \frac{I_{\mathrm{E}}}{I_{\mathrm{s}}}
$$

were, $\dot{m}_{\mathrm{p}} \gg \dot{m}_{\mathrm{s}}$ is assumed and the small term is ignored.

The effective specific impulse of the secondary flow can be obtained from Eq. (2) by comparing the engine specific impulse with and without the secondary flow. Initially, the specific impulses for various secondary flow injection rates were measured and then the effective specific impulse of the secondary flow was evaluated by comparison with the data for a smooth nozzle without secondary injection. However, the effective specific impulse of the secondary flow obtained in this way was widely scattered, especially for small secondary flow rates due to run-to-run reproducibility of performances. As Eq. (5) shows, run-to-run reproducibility of performances become important when computing the effective specific impulse of the secondary flow because the secondary flow ratio in this experiment is $1 \%$ to $5 \%$. The estimated precision of the engine specific impulse is approximately $1 \%$ with most of the error attributable to the measurement of hydrogen and oxygen mass flow rates. ${ }^{1)}$ The reproducibility of the engine specific impulse during a long-term ( $>6$ months) testing period was about $1 \%$ and run-to-run reproducibility of the engine specific impulse under the same testing period was within $0.5 \%$. If we assume the engine specific impulse is $440 \mathrm{~s}$ and the effective specific impulse of the secondary flow are $300 \mathrm{~s}$, Eq. (5) shows that the run-to-run reproducibility of the performances must be no more than $0.1 \%$ in obtaining the effective specific impulse of the secondary flow within $20 \%$ of the error. However, this is almost impossible to achieve in different experiments conducted in different testing periods. The fluctuation of the engine specific impulse (averaged every single second) was within $0.2 \%$ and most cases were within $0.1 \%$ for more than $15 \mathrm{~s}$ firing duration tests. When the secondary injection ratio is set to $1 \%, 3 \%$, and $5 \%$, the effective specific impulse of the secondary flow obtained by shutting off the secondary injection during the same run can be obtained within errors of $20 \%, 6.6 \%$, and $4.0 \%$, respectively.

All experiments were conducted at the former National Aerospace Laboratory's high altitude test facility for rocket engines. The capsule pressure was about $1 \mathrm{kPa}$ ( 8 Torr). The nominal operating conditions and performance parameters of the primary flow are shown in Table 1 along with the primary and secondary flow parameters, which are required to calculate the specific impulse of the secondary flow. The combustion chamber of the LE-5 engine is initially cooled with $\mathrm{LH}_{2}$ and then supplied to the combustion chamber at $140 \mathrm{~K}$ under super-critical condition. To simulate this condition, $\mathrm{LH}_{2}$ and $\mathrm{GH}_{2}$ were mixed to produce $140 \mathrm{~K}$ supply gas $\left(T_{\mathrm{HP}}=140 \mathrm{~K}\right)$. Another supply gas $\left(T_{\mathrm{HP}}=290 \mathrm{~K}\right)$ was used to investigate the effect of the fuel supply temperature on the combustion chamber. 
To eliminate the run-to-run reproducibility error, the secondary flow was injected during the initial $18 \mathrm{~s}$ and was shut off in the remaining 4 to $6 \mathrm{~s}$ of the firing duration. The stable specific impulse without secondary flow was obtained within $4 \mathrm{~s}$.

\section{Numerical Condition}

The numerical conditions in the present study are set to be equivalent to the experimental conditions and are shown in Table 1. The secondary flow is injected under sonic conditions and is injected parallel to the nozzle axis. The stagnation temperature and chemical mass fraction inside the combustion chamber are obtained by computing the chemical equilibrium. ${ }^{6}$ The $\mathrm{LOX} / \mathrm{GH}_{2}$ condition with an input enthalpy of $290 \mathrm{~K}$ is used for the chemical equilibrium computation and the stagnation temperature $\left(T_{0}\right)$ is obtained as $3407 \mathrm{~K}$. Correction of the $\mathrm{C}^{*}$ efficiency is not considered in this chemical equilibrium computation. The obtained chemical mass fractions inside the combustion chamber are shown in Table 2. The chemical mass fractions are used as input conditions for the inlet boundary conditions inside the combustion chamber. The isothermal wall temperature is assumed to be $300 \mathrm{~K}$ and $800 \mathrm{~K}$. Non-slip, and non-catalytic conditions are applied for the wall boundary conditions. The wall temperature of $300 \mathrm{~K}$ represents the low wall temperature with water cooling and $800 \mathrm{~K}$ represents the combustion chamber region and actual full scale nozzle design point.

The boundary layer condition is investigated by computing the throat Reynolds number $\left(R e_{\mathrm{t}}\right)$ using the TDK ${ }^{7)}$ code. The value of $R e_{\mathrm{t}}$ is obtained using viscous coefficients $\mu$, density $\rho$, and velocity $u$ at the throat region. The character-

Table 1. Nominal operating conditions.

\begin{tabular}{lccc}
\hline \multicolumn{1}{c}{ Item } & Unit & $T_{\mathrm{HP}}=140 \mathrm{~K}$ & $T_{\mathrm{HP}}=290 \mathrm{~K}$ \\
\hline Chamber pressure & $\mathrm{MPa}$ & 3.48 & 3.48 \\
Mixture ratio & & 5.5 & 5.5 \\
Throat diameter & $\mathrm{mm}$ & 28 & 28 \\
Primary nozzle area ratio & & 140 & 140 \\
Injection area ratio & & 13 & 13 \\
Nozzle exit angle & $\mathrm{deg}$ & 10.7 & 10.7 \\
Thrust & $\mathrm{N}$ & 3964 & 3941 \\
$C^{*}$ efficiency & & 0.955 & 0.975 \\
Nozzle exit pressure ratio & & $7.099 \times 10^{-4}$ & $7.296 \times 10^{-4}$ \\
Sec. hydrogen temp. & $\mathrm{K}$ & 280 & 290 \\
Sec. charac. velocity & $\mathrm{m} / \mathrm{s}$ & 1516 & 1543 \\
CFV efficiency & & 0.959 & 0.947 \\
Theoretical thrust coeff. & & 1.997 & 2.004 \\
Primary vac. $I_{\mathrm{sp}}$ & $\mathrm{s}$ & 438 & 438 \\
\hline
\end{tabular}

istic length is the throat diameter $(L=0.028 \mathrm{~m})$. The value of $R e_{\mathrm{t}}$ is defined as follows:

$$
R e_{\mathrm{t}}=\frac{\rho u L}{\mu}
$$

Here, the input wall temperature is set to $800 \mathrm{~K}$ and the mixture ratio is set to 5.5 , which is the same condition used for the CFD computations. Table 3 shows the obtained $R e_{\mathrm{t}}$. From Table 3 , the $R e_{\mathrm{t}}$ is $4.7 \times 10^{5}$. From the obtained $R e_{\mathrm{t}}$, the boundary layer is assumed to be in its transition region. ${ }^{8)}$ Therefore, both laminar and turbulent computations are carried out.

\section{Numerical Method and Computational Grid}

The numerical code used in this study is outlined elsewhere. ${ }^{9)}$ The governing equations are three-dimensional compressible Navier-Stokes equations with conservative equations for multi-species. The chemical species are $\mathrm{H}_{2}$, $\mathrm{O}_{2}, \mathrm{O}, \mathrm{H}, \mathrm{OH}, \mathrm{HO}_{2}, \mathrm{H}_{2} \mathrm{O}_{2}, \mathrm{H}_{2} \mathrm{O}$, and $\mathrm{N}_{2}$. The stiffness problem arises when solving supersonic reactive flows numerically because the characteristic reaction time is significantly smaller than the characteristic fluid flow time. Therefore, a linearly point implicit technique is used to solve the source term including the chemical reaction and a LU-ADI factorization algorithm ${ }^{10)}$ is used for integration in time. The convective terms are obtained by AUSM-DV ${ }^{11)}$ and secondorder space accuracy is evaluated using MUSCL with a minmod function. The viscous terms are calculated by central differencing. The Petersen and Hanson model ${ }^{12)}$ including 9 species and 18 elementary reactions is used to calculate the chemical reaction. This reaction model was proposed for computing detonation and supersonic combustion flow achieving local pressures higher than $100 \mathrm{~atm}$. The validation for applying this reaction model to these kinds of flow fields is presented elsewhere. ${ }^{13)}$ It can be assumed that the present reaction model is sufficiently reliable for application to the present rocket nozzle flow computation. The eddy viscosity is evaluated using the Baldwin-Lomax turbulence model with the Degani-Shiff correction.

The computational grid system is shown in Fig. 2. The computation is carried out for a single secondary injection hole region which is $12 \mathrm{deg}$. in circumferential direction and the grid points are $201 \times 31 \times 77$. For discussions of quantitative specific impulse performance, the minimum grid size near the wall surface is set to $0.5 \mu \mathrm{m}$. We showed

Table 3. LE-5 sub-scale engine throat Reynolds number (SI units).

\begin{tabular}{cccccc}
\hline MR & $\mu$ & $u$ & $\rho$ & $L$ & $R e_{\mathrm{t}}$ \\
\hline 5.5 & $8.78 \times 10^{-5}$ & 1543 & 0.95 & 0.028 & $4.67 \times 10^{5}$ \\
\hline
\end{tabular}

Table 2. Chemical mass fractions inside combustion chamber.

\begin{tabular}{|c|c|c|c|c|c|c|c|c|}
\hline $\mathrm{H}_{2}$ & $\mathrm{O}_{2}$ & $\mathrm{O}$ & $\mathrm{H}$ & $\mathrm{OH}$ & $\mathrm{HO}_{2}$ & $\mathrm{H}_{2} \mathrm{O}_{2}$ & $\mathrm{H}_{2} \mathrm{O}$ & $\mathrm{N}_{2}$ \\
\hline 0.048722 & 0.008716 & 0.00555 & 0.003995 & 0.06209 & 0.000089 & 0.000016 & 0.870822 & 0.0 \\
\hline
\end{tabular}




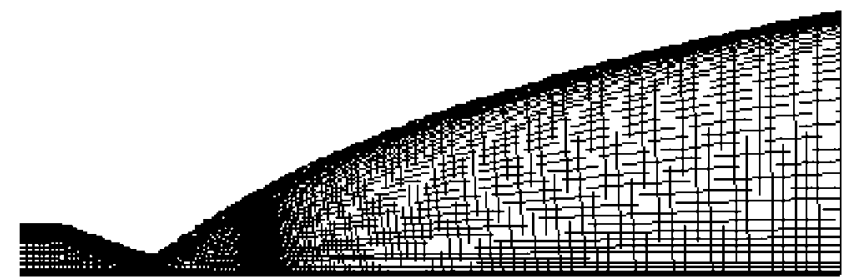

Fig. 2. Computational grids for CFD.

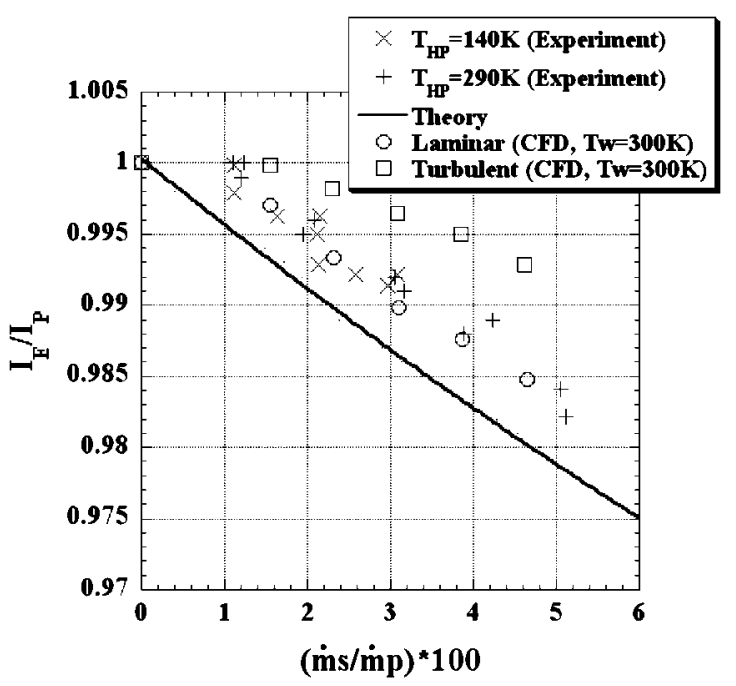

Fig. 3. Influence of film cooling ratio on engine specific impulse $\left(T_{\mathrm{w}}=300 \mathrm{~K}\right)$.

that the specific impulse performance is insensitive to the grid resolution near the wall and the difference is less than 1 sec. $^{9)}$

\section{Results and Discussions}

\subsection{Film cooling effect on nozzle performance}

\subsubsection{Comparison with experiment}

The nozzle extension region (film cooling region) is circumferentially cooled by the water as shown in Fig. 1. Therefore, the wall temperature is assumed to be close to $300 \mathrm{~K}$ than $800 \mathrm{~K}$. The temperatures measured at the rand of the circumferential cooling channels in the depth of about $3 \mathrm{~mm}$ from the gas-side surface were at the 1st segment 465 $340 \mathrm{~K}$, 2nd segment 400-290 K, and 3rd segment 370$320 \mathrm{~K}$, respectively. From these values and obtained heat fluxes, the gas side wall temperature were estimated to be $500-350 \mathrm{~K}$ at the 1 st segment, $500-420 \mathrm{~K}$ at the 2 nd segment, and $420-375 \mathrm{~K}$ at the $3 \mathrm{rd}$ segment, respectively. Considering the film cooling effect, the wall temperature was about $10 \mathrm{~K}$ lower than the above value and is measured to be around 460-330 K. To represent the cold wall temperature, i.e., water cooled or fuel cooled wall; wall temperature is set to $300 \mathrm{~K}$ in the computations.

Figure 3 shows the ratio of the engine specific impulse to the primary engine specific impulse against the film cooling ratio. The symbols $\times$ and + represent the data obtained from the experiment and the temperatures shown in the explanatory notes are the hydrogen supply temperature to the injec-

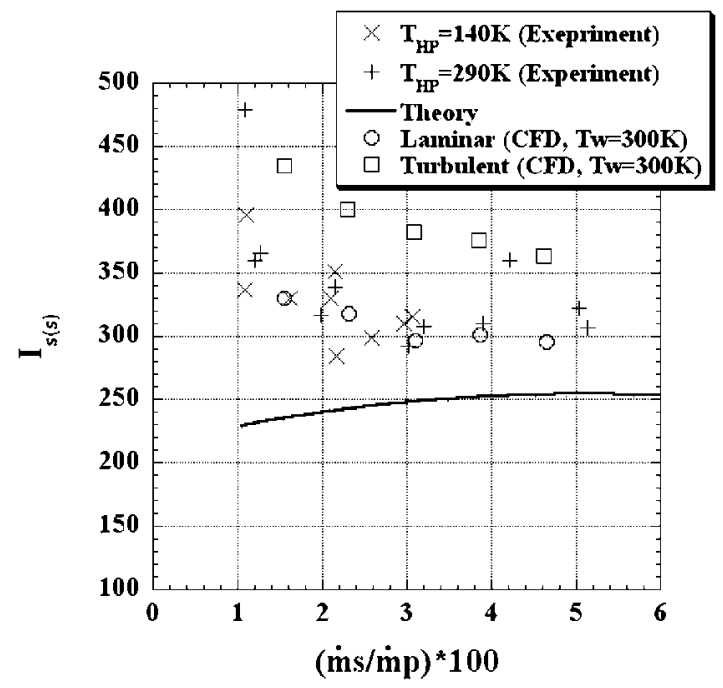

Fig. 4. Effective specific impulse of secondary flow $\left(T_{\mathrm{w}}=300 \mathrm{~K}\right)$.

tor. ${ }^{1)}$ The solid lines in Figs. 3 and 4 are obtained assuming that the throat area is the sum of the areas of the injection ports and the injected secondary flow expands isentropically from the manifold pressure to the nozzle exit pressure. It is also assumed that the main flow nozzle exit pressure is not influenced by the secondary flow but the displacement effect of the main flow due to the secondary flow is considered. ${ }^{14)}$ From Fig. 3, a large difference in performance is observed between turbulent and laminar flows. Figure 3 also shows that the results of laminar flow are in quantitative agreement with the experimental ones. The effective specific impulse of the secondary flow is shown in Fig. 4. The effective specific impulse of the secondary flow is obtained from Eq. (2). Again, the computed effective specific impulses of the secondary flow assuming laminar flow and those of the experiments agree quantitatively. The theoretical specific impulse of the secondary flow is around $250 \mathrm{~s}$ and becomes slightly lower as the film cooling ratio decreases. However, the experimental specific impulse increases and is distributed between $300 \mathrm{~s}$ and $350 \mathrm{~s}$ when the secondary flow decreases. The results of the laminar computations agree quantitatively with the experiment (Fig. 4). However, the computed turbulent results qualitatively follow the same trend as the experiment although they are about $50 \mathrm{~s}$ higher than the experimental data. Since the laminar computation with low wall temperature agrees well with the experiment, the flow is assumed to be laminar. We previously showed that the heat flux and the boundary layer loss in the numerical simulation are in good agreement with the experiment using the subscale clean nozzle under laminar conditions. ${ }^{9)}$ This conclusion is consistent with the present results. The mixing flow field discussed here is $3 \mathrm{D}$ and very different from that assumed in the simple theory. ${ }^{14)}$ Therefore, clearly the simple theory does not match the experiment quantitatively.

\subsubsection{Effect of high-temperature wall on nozzle per- formance}

The effect of the secondary flow on the nozzle performance is assumed to depend on the boundary layer condition 


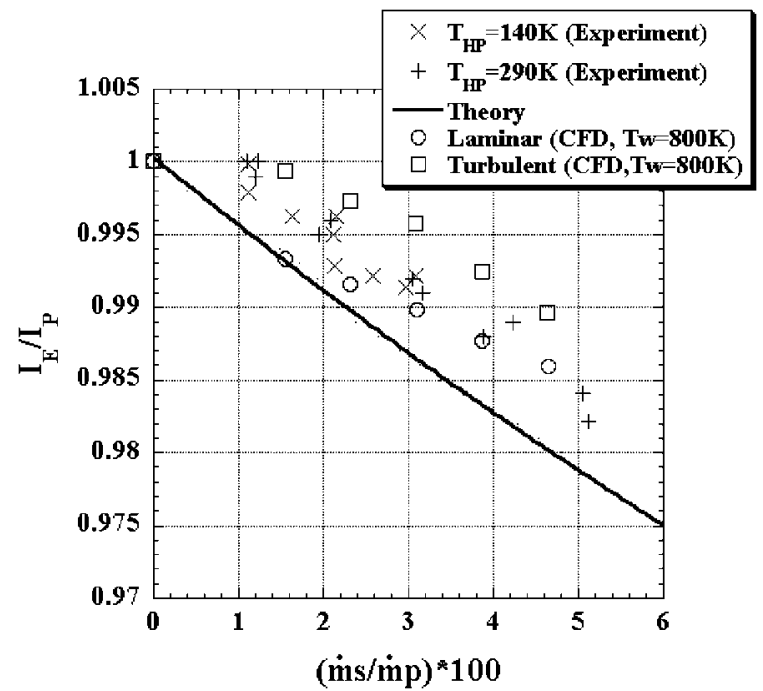

Fig. 5. Influence of film cooling ratio on engine specific impulse $\left(T_{\mathrm{w}}=800 \mathrm{~K}\right)$.

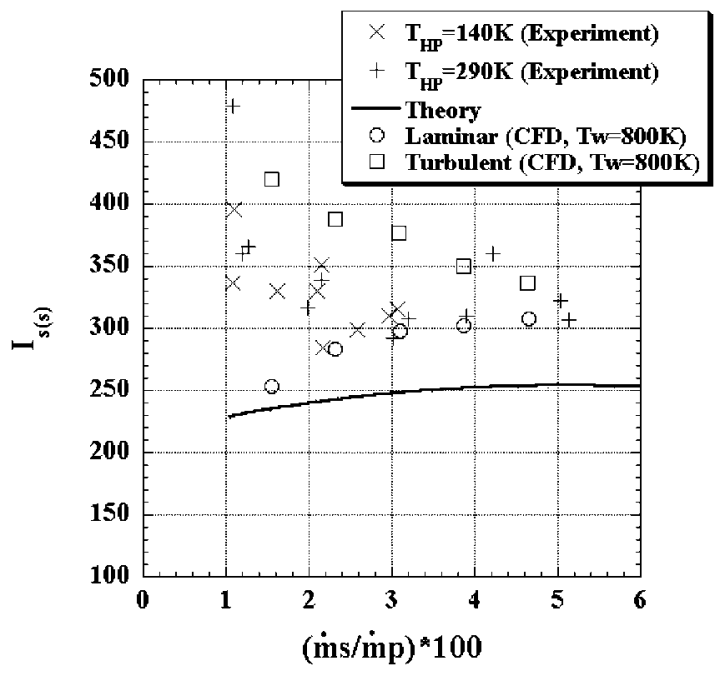

Fig. 6. Effective specific impulse of secondary flow $\left(T_{\mathrm{w}}=800 \mathrm{~K}\right)$.

inside the film cooling layer. The boundary layer conditions may differ with wall temperatures. Some actual engines, using regenerative cooling may actively cool the nozzle extension region. However, some engine types may not. For example, the LE-5B engine powering the second stage of the H-IIA launch vehicle protects the nozzle extension from heating by dump-cooling in the upstream region and film cooling in the downstream thin metal region utilizing the turbine drive gas. The nozzle wall temperature downstream of the film cooling injection region varies between $600 \mathrm{~K}$ and $1000 \mathrm{~K}$. The effect of the high wall temperature on the nozzle performance was investigated by CFD using the $800 \mathrm{~K}$ wall temperature. Figures 5 and 6 show the results corresponding to Figs. 3 and 4 but with a wall temperature of $800 \mathrm{~K}$. From comparison of the turbulent condition with Figs. 3 and 4, the effective specific impulse of the secondary flow is slightly lower at the $800 \mathrm{~K}$ wall temperature although most of the qualitative dependence on the secondary flow is similar. The main difference is observed at laminar conditions. The effective specific impulse at high wall tempera-

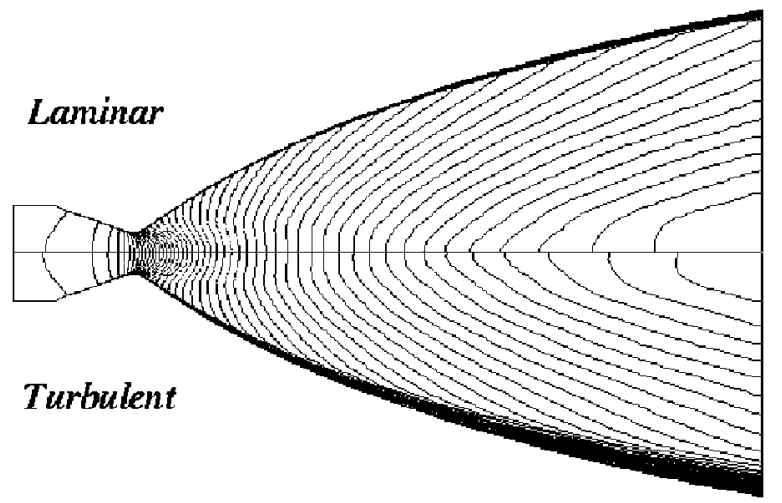

Fig. 7. Comparison between laminar and turbulent computation (Mach number distributions-without film cooling injection).

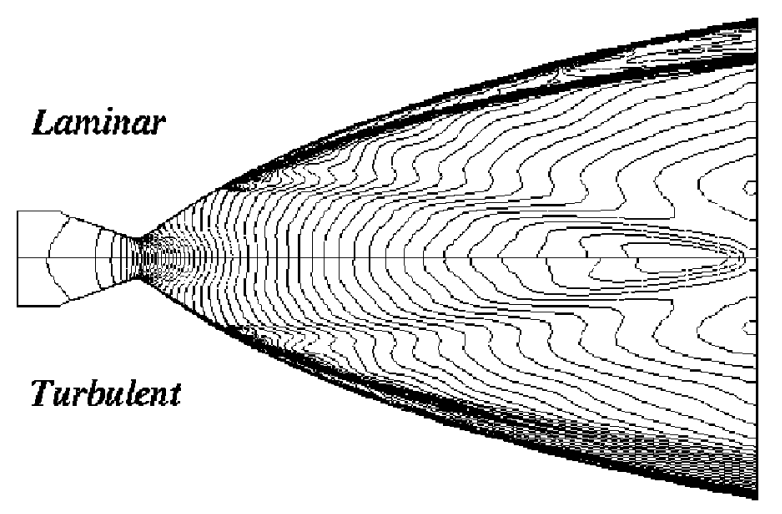

Fig. 8. Comparison between laminar and turbulent computation (Mach number distributions-with film cooling injection).

ture decreases as secondary flow ratio decreases (Fig. 6). The opposite trend for low wall temperature conditions is seen in Fig. 4.

\subsection{Influence of film cooling on flow field}

The computed case for the $300 \mathrm{~K}$ wall temperature is discussed in sections 5.2.1. and 5.2.2. The influence of wall temperature on the flow field and boundary layer is discussed in section 5.2.3.

\subsubsection{Difference between laminar and turbulent flows}

The Mach number distribution of the laminar (upper half) and turbulent (lower half) flow field inside the nozzle without film cooling injection is shown in Fig. 7 for a reference. The turbulent boundary layer becomes thicker than the laminar boundary layer due to turbulent dissipation. Although the difference appears at the boundary layer region, the Mach number contour plots in the nozzle core region are very similar. This shows that the difference in boundary layer does not influence the main core flow.

Mach number distributions with film cooling injections are shown in Fig. 8. Again, the upper half shows the laminar flow field and lower half shows the turbulent flow field. Here, the stagnation pressure of the film cooling injection is $0.4 \mathrm{MPa}$. The shock wave appears due to the interaction of the secondary flow and the main flow. Small mixing between the film coolant and core flow occurs with the laminar condition and a clear film cooling layer exists near the nozzle wall. However, the film cooling mixing layer devel- 


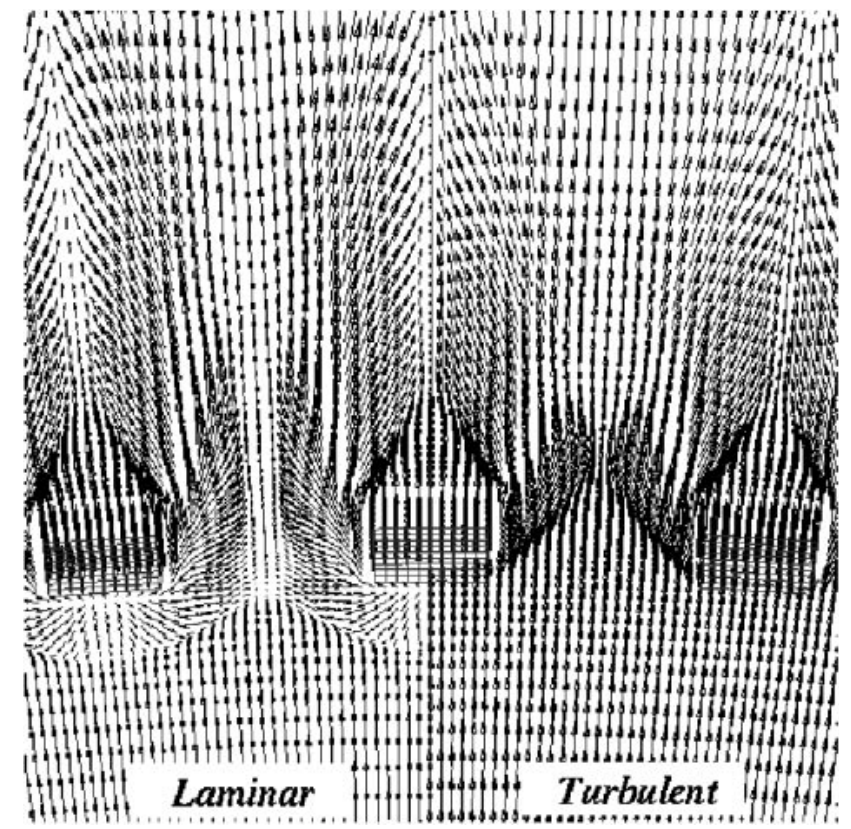

Fig. 9. Velocity vectors inside film cooling layer.

ops as the film cooling flows down stream and becomes thick under the turbulent condition. Clearly, the film cooling layer becomes substantially thicker than when film coolant is not injected (Fig. 7).

\subsubsection{Discussions of film cooling flow field}

The velocity vector plots inside the film cooling layer are shown in Fig. 9. The left side of the plots is drawn under laminar conditions and the right side is drawn under turbulent conditions. The plots are drawn at the $y^{+}=656.8$ part. The injection holes are shown by the grids. The upper part of the figure is the downstream direction. From the laminar velocity vector plots, flow separation occurs upstream of the injection holes and reverse flow from the injection holes is clearly observed. There is some reverse flow between the injection holes and flow downstream. The main component of the reverse flow is the gasified hydrogen used as film coolant. In the turbulent plots, the separation region is small compared to the laminar condition and the amount of reverse flow is small.

Figures 10 and 11 show the Mach number distributions inside the nozzle for laminar and turbulent conditions, respectively. Each cross section corresponds to the $x=0.0645 \mathrm{~m}, 0.145 \mathrm{~m}, 0.217 \mathrm{~m}, 0.3145 \mathrm{~m}$, and $0.427 \mathrm{~m}$ region from the nozzle throat, respectively. In these figures, the computed region (12 deg) is arranged circumferentially five times so the flow visualization is clearer. The phase where the film cooling effect propagates toward the nozzle axis in Fig. 10 corresponds to the phase where there is film injection hole. The effect of film cooling is observed between the injection hole phases from Fig. 10. This is caused by the reverse flow from the injection hole, which flows between the injection holes as discussed in Fig. 9. In Fig. 11, the effect of film cooling between the injection holes is not clearly observed compared to Fig. 10 because the amount of the reverse flow from the injection holes is

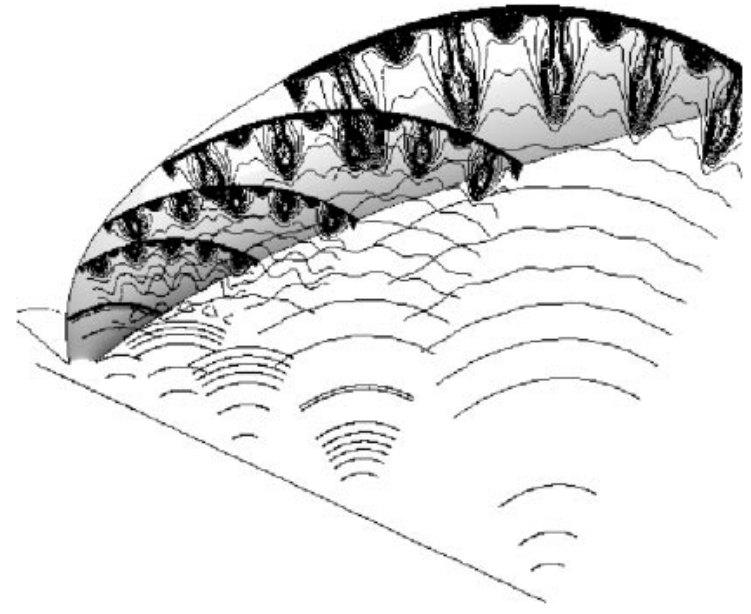

Fig. 10. Mach number distributions inside nozzle (Laminar).

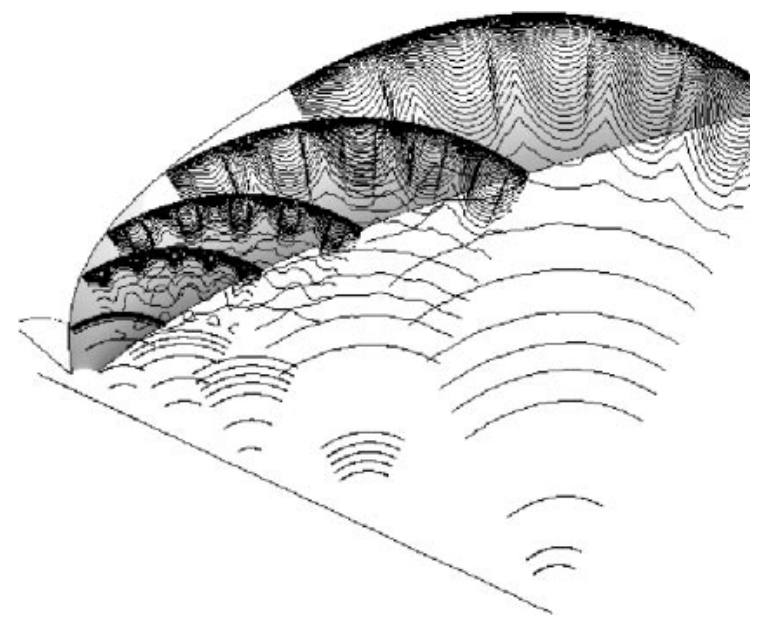

Fig. 11. Mach number distributions inside nozzle (Turbulent).

small compared to the laminar conditions. Figures 10 and 11 show the clear difference between laminar and turbulent flow structures.

\subsubsection{Effect of wall temperature on boundary layer structure}

The Mach number distributions at the nozzle exit for the film cooling injection hole phase during laminar CFD computations are shown in Fig. 12. The film cooling layer region for the $300 \mathrm{~K}$ wall temperature is at $5.1 \leq r / r^{*} \leq 5.7$ and the boundary layer inside the film cooling layer is at $5.7 \leq r / r^{*} \leq 5.91$ from Fig. 12 . At the $800 \mathrm{~K}$ wall temperature, the film cooling layer is at $4.9 \leq r / r^{*} \leq 5.4$ and the boundary layer inside the film cooling layer is at $5.4 \leq r / r^{*} \leq 5.91$. Clearly, the boundary layer inside the film cooling layer is thicker for the $800 \mathrm{~K}$ wall temperature compared to the $300 \mathrm{~K}$ wall temperature.

The Mach number distributions at the nozzle exit for the phase between the film injection holes are shown in Fig. 13. Again, the computed data are plotted under the laminar condition. The flow region, which is influenced by the film coolant, is small for the phase between the film injection holes. As discussed in Fig. 12, the boundary layer inside the film cooling layer becomes thicker at the higher nozzle wall tem- 


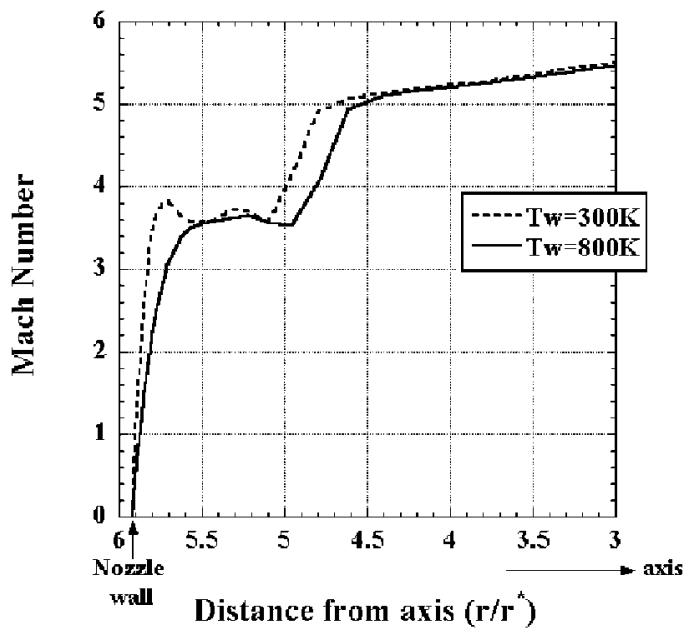

Fig. 12. Mach number distributions at nozzle exit (film injection hole phase-laminar).

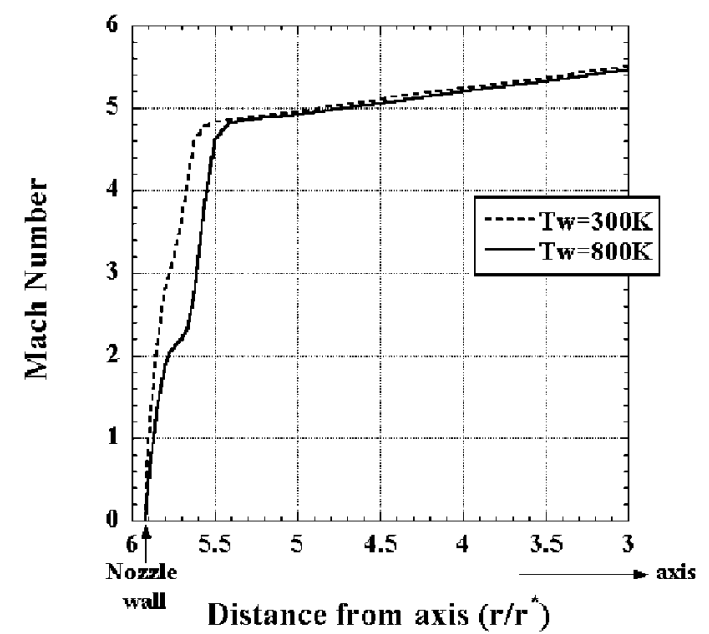

Fig. 13. Mach number distributions at nozzle exit (between film injection hole phase-laminar).

perature conditions.

From the computed results in Figs. 12 and 13, clearly the boundary layer at high wall temperatures is thicker than at low wall temperatures. The film coolant temperature is set to $290 \mathrm{~K}$ and the temperature difference between the film coolant and wall temperature for the $800 \mathrm{~K}$ wall temperature is larger than the $300 \mathrm{~K}$ wall temperature. Therefore, the thermal boundary layer is thicker for the $800 \mathrm{~K}$ nozzle wall temperature than for the $300 \mathrm{~K}$ nozzle wall temperature. Figures 5 and 6 are plotted at the $800 \mathrm{~K}$ nozzle wall temperature and the boundary layer is thick. On the other hand, Figs. 3 and 4 are plotted for the $300 \mathrm{~K}$ nozzle wall temperature and the boundary layer becomes thin and leads to laminar conditions. As mentioned, the nozzle wall temperature is assumed to be closer to $300 \mathrm{~K}$ in the present tests. However, the full-scale rocket engine nozzle is not water cooled and the hot wall temperature boundary condition can be suitable. In either case, it is best to obtain wall temperature from the computed flow field rather than to input the isothermal wall condition as the boundary condition.

\section{Conclusions}

The LE-5 sub-scale rocket engine nozzle flow field with film cooling injection (secondary flow) into the supersonic core nozzle flow was computed using CFD. The effect of film cooling injection on engine performance was evaluated by computing both the laminar and turbulent conditions. The conclusions are as follows:

1) The computed effective specific impulse of the secondary flow with low wall temperature showed good agreement with the experiment under laminar conditions.

2) A large difference was observed in the effective specific impulse of the secondary flow between the laminar and turbulent conditions.

3) A large reverse flow region appeared upstream of the injection hole and a substantial reverse flow was induced between injection holes in the laminar condition. In the turbulent condition, no main flow separation upstream of the injection hole was observed and hardly any coolant flow was induced between injection holes.

4) The computed boundary layer for laminar conditions at the $300 \mathrm{~K}$ wall temperature was thin and the specific impulse showed good agreement with the experiments.

5) The influence of wall temperature must be taken into account when evaluating nozzle performance with film cooling.

Evaluation of wall temperature by CFD computation requires more advanced modeling than used here and remains a future issue. We suggest that computation of nozzle performance with film cooling requires distinction between high and low nozzle wall temperature conditions.

\section{Acknowledgments}

This study was performed using the JAXA super computer system SSS.

\section{References}

1) Miyajima, H., Kusaka, K. and Sogame, E.: Effective Specific Impulse of Secondary Flow Injected into a Rocket Nozzle, NAL TR-848T, 1984.

2) Haidinger, F.: Influence of Turbulence Modeling on the Performance Prediction for Rocket Engine Nozzles, J. Propul. Power, 15 (1999), pp. 523-529.

3) Yanagawa, K., Fujita, T., Miyajima, H. and Kishimoto, K.: HighAltitude Simulation Tests of the LOX/LH $\mathrm{L}_{2}$ Engine LE-5, J. Propul. Power, 1 (1985), pp. 180-186.

4) Miyajima, H., Moro, A., Kusaka, K., Nakahashi, K., Kuroda, Y., Kumagai, T., Kisara, K., Kamata, M., Sato, M., Abe, N. and Katsuta, H.: Experimental Performance of a Small LOX/ $\mathrm{H}_{2}$ Thrust Chamber with a High Area Ratio Nozzle (1), Technical Report of National Aerospace Laboratory, NAL TR-662, 1981 (in Japanese).

5) Abernethy, R. B., Colbert, D. L. and Powell, B. D.: ICRPG Handbook for Estimating the Uncertainty in Measurements Made with Liquid Propellant Rocket Engine Systems, CPIA No. 180, April 1969.

6) Gordon, S. and McBride, B.: Computer Program for Calculation of Complex Chemical Equilibrium Compositions, Rocket Performance, Incident and Reflected Shocks, and Chapman-Jouget Detonations, NASA SP-273, 1971.

7) Nakahashi, K., Miyajima, H., Kisara, K. and Moro, A.: Prediction 
Method of Rocket Nozzle Performance, Technical Report of National Aerospace Laboratory, NAL TR-771, 1983 (in Japanese).

8) Schoenman, L.: Low-Thrust Isp Sensitivity Study, NASA CR-165621, 1982.

9) Tsuboi, N., Ito, T. and Miyajima, H.: Numerical study and performance prediction for gaseous hydrogen/oxygen bell nozzle, T. Jpn. Soc. Aeronaut. Space Sci., 51 (2008), pp. 86-92.

10) Fujii, K.: Practical Applications of New LU-ADI Scheme for the Three-Dimensional Navier-Stokes Computation of Transonic Viscous Flows, AIAA Paper 86-0513, 1986.

11) Wada, Y. and Liou, M.-S.: A Flux Splitting Scheme with High-Reso- lution and Robustness for Discontinuities, AIAA Paper 94-0083, 1994.

12) Petersen, E. L. and Hanson, R. K.: Reduced Kinetics Mechanisms for Ram Accelerator Combustion, J. Propul. Power, 15 (1999), pp. 591600 .

13) Tsuboi, N., Eto, K. and Hayashi, A. K.: Detailed Structure of Spinning Detonation in a Circular Tube, Combust. Flame, 149 (2007), pp. 144161.

14) Stromsta, R. R. and Hosak, G. A.: Analytical Methods for Computing the Effects of Turbine Exhaust and Film-Coolant Injection on Rocket Engine Performance, AIAA Paper 69-472, 1969. 